\title{
Comparative study of the cellulolytic activity of caecum microbes in ponies and donkeys
}

\author{
F Faurie, JL Tisserand
}

\section{Laboratoire Associé de Recherches Zootechniques INRA-ENSSAA, 26, bd Docteur-Petitjean, 21000 Dijon, France}

In the context of comparative research on the digestive physiology of donkeys and ponies we have compared the in sacco degradation of fodder in the caeca of donkeys and ponies.

Three adult ponies and 3 adult donkeys with permanent caecum cannulas (225 and $248 \mathrm{~kg}$ live weight, respectively) were given a pelleted feed made up of wheat straw, maize grain and soya cake (crude protein $\mathrm{CP}$ in dry matter $\mathrm{DM}=$ $12.1 \%$; NDF $=64.2 \% ; A D F=33.4 \%$ ) ,at the maintenance level. After a $15 \mathrm{~d}$ adaptation period, the straw degradation in the caecum $(\mathrm{CP}=3.5 \% \mathrm{DM}$; $\mathrm{NDF}=77.1 \% ; \mathrm{ADF}=46.5 \%$; $\mathrm{CF}=42.4 \%$ ) was assessed by the nylon-bag technique (Miraglia et al, 1988) as follows: 1) degradation after $24 \mathrm{~h}$; 2) degradation after $48 \mathrm{~h} ; 3$ ) degradation after 24 $h$ in one species and $24 h$ in the other; with 3 repetitions per animal, ie 9 results per treatment.
Determination of the cell-wall content was according to Van Soest (1963).

Figure 1 shows that after 24 and $48 \mathrm{~h}$ the straw NDF and ADF DM degradation is higher in the donkeys than in the ponies. These results are statistically significant for a $\mathbf{4 8} \mathrm{h}$ degradation period. The increase in DM, NDF and ADF degradation is higher in donkeys after a period of 24 $h$ in ponies than in ponies after a $24 \mathrm{~h}$ period in donkeys.

These results show that the capacity of the caecum to degrade cell walls is higher in donkeys than in ponies.

Miraglia N, Martin-Rosset W, Tisserand JL (1988) Ann Zootech 37, 13-20

Van Soest PJ (1963) J Am Off Agric Chim 46, 829-835
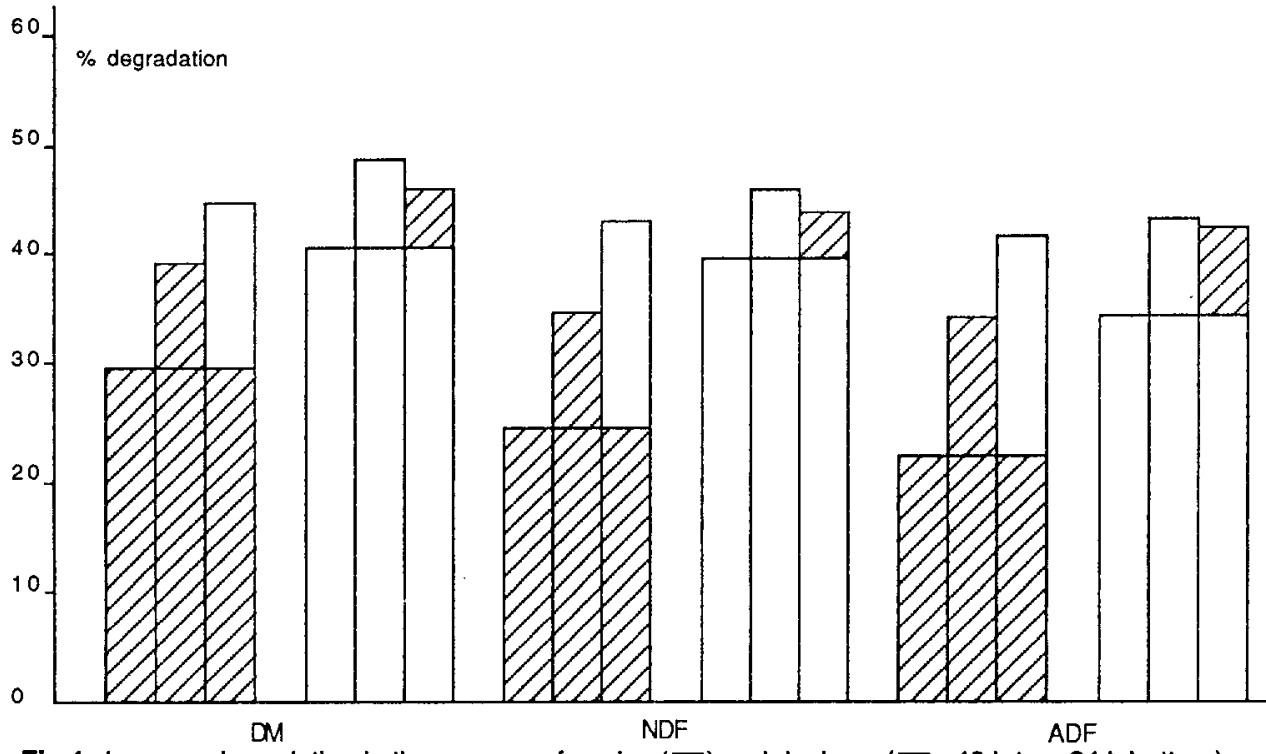

Fig 1. In sacco degradation in the caecum of ponies ( 